\title{
POST-OPERATIVE RENAL FAILURE CAUSED BY DISSEMINATED INTRAVASCULAR COAGULATION
}

\author{
Alexander W. Gotta, Dorothy Murray, Colleen A. Sullivan, \\ and John SEaman
}

By A PROCEss of thrombotic obstruction of the renal vasculature, the phenomenon of disseminated intravascular coagulation (DIC) can cause oliguric renal failure. While this postulate has been adequately demonstrated experimentally, ${ }_{2}^{1,2}$ the clinical occurrence in the patient subjected to anaesthesia and surgery has received little recognition, ${ }^{3}$ and probably not consonant with its true incidence. We present a case of renal failure following trauma, anaesthesia and operation, with a discussion of the role of DIC as the cause and the contribution made by anaesthesia.

\section{Case Report}

The patient was a 22-year-old male admitted to St. Mary's Hospital with a stab wound of the upper left thigh. He was an alcoholic and two years previously had hepatitis. On physical examination he was in obvious hypovolaemic shock, pale, sweaty, with dilated pupils, a weak and thready pulse and blood pressure of $60 / 40$. The left quadriceps muscle was cut across and shredded and the femoral artery and vein were transected and bleeding profusely. In blood drawn prior to operation the B.U.N. was $15 \mathrm{mg}$ per cent and the creatinine $1.6 \mathrm{mg}$ per cent. A three-hour repair of the femoral artery and vein was performed, with the patient anaesthetized with cyclopropane in oxygen. Following this operation no pulses were palpable distal to the anastomosis, and femoral embolectomy was then performed. During the procedure the blood pressure ranged from $90 / 60-110 / 60$, and pulse from 120-100. He received seven units of packed cells, $500 \mathrm{ml}$ of Albumisol and $2000 \mathrm{ml}$ of lactated Ringer's solution. Post-operatively he received 5000 units of heparin intravenously every six hours for two days.

On the first post-operative day the foot was warm and pulses palpable. Blood drawn prior to heparin administration revealed that partial thromboplastin time and prothrombin time were prolonged, platelet count depressed and fibrinogen level decreased (see table). Electrolytes were within normal limits except potassium $3.0 \mathrm{meq} / \mathrm{L}$.

On the second post-operative day his leg was markedly oedematous, white, cold and pulseless, with non-clotting blood oozing freely from the wound site. The area was explored again and the leaking arterial anastomosis repaired. The patient received cyclopropane/ether/oxygen anaesthesia for one hour and fifteen minutes. Blood pressure varied from $90 / 55-180 / 90$ and pulse from $120-130$. He received

From the Departments of Anesthesiology and Medicine, St. Mary's Hospital, Brooklyn, New York, Catholic Medical Center of Brooklyn and Queens. 
TABLE I

SUMMARY OF LABORATORY DATA

\begin{tabular}{|c|c|c|c|c|c|c|}
\hline $\begin{array}{c}\text { Post- } \\
\text { Operative } \\
\text { Day }\end{array}$ & $\mathrm{PT}$ & PTT & $\begin{array}{l}\text { Fibrinogen } \\
\text { mg\% }\end{array}$ & Platelets & $\begin{array}{c}\text { Staph } \\
\text { Clumping }\end{array}$ & $\begin{array}{c}\text { *Thrombin } \\
\text { Time }\end{array}$ \\
\hline 1 & $\frac{35}{11.8}$ & $\frac{52}{31}$ & 37 & 60,000 & - & - Post-Op. \\
\hline 6 & $\frac{17}{13}$ & $\frac{32}{31}$ & 324 & 100,000 & $+1 / 64$ & $\begin{array}{l}\text { 27/13 After } \\
\text { Heparin } \\
\text { for } 6 \mathrm{~d}\end{array}$ \\
\hline 8 & $\frac{16}{14}$ & $\frac{49}{45}$ & 391 & - & - & $\begin{array}{c}\text { 17/10 After } \\
\text { Heparin } \\
\text { for } 9 \mathrm{~d}\end{array}$ \\
\hline
\end{tabular}

two units of packed cells, $1000 \mathrm{ml} 5$ per cent dextrose in lactated Ringer's solution and $300 \mathrm{ml}$ of lactated Ringer's solution. At the beginning of anaesthesia and operation the electrocardiogram demonstrated tall, peaked T-waves, widening of the QRS complex and absent $\mathrm{P}$ waves. The administration of NaHCO3 (three ampoules of $44.6 \mathrm{mEq}$ each), plus $200 \mathrm{ml}$ of 5 per cent glucose in water and 10 units regular insulin returned the ECG pattern to normal. Calcium was not given because of the rapid reversion to normal. Arterial blood drawn after $44.6 \mathrm{meq}$ of $\mathrm{NaHCO}_{3}$ revealed $\mathrm{pH} 7.26, \mathrm{Pco}_{2} 44$ torr, Po.. 255 torr bicarbonate $19 \mathrm{meq} / \mathrm{L}$, and potassium $8 \mathrm{meq} / \mathrm{L}$. This metabolic acidosis persisted into the postoperative period despite treatment, and was accompanied by hyperkalaemia (potassium up to 8.1 meq/L) and azotaemia (BUN up to $180 \mathrm{mg}$ percent, creatinine up to $14.4 \mathrm{mg}$ per cent). Oliguria persisted, unresponsive to either furosamide or mannitol, with daily urine outputs of $500 \mathrm{ml}$ until the 14th postoperative day, when he began to excrete 4 to 5 liters per day. During the oliguric phase he was maintained by peritoneal dialysis. Heparin was continued in an intravenous drip of 500 units per hour, and did not occasion any bleeding associated with the dialysis. The heparin was continued for four days, and then replaced with sodium warfarin in doses decreasing from $30 \mathrm{mg}$ per day to $5 \mathrm{mg}$ per day over a four-day period. He was discharged while still receiving warfarin.

On the 6 th post-operative day fibrinogen was $324 \mathrm{mg}$ per cent, prothrombin time 17 seconds (control 13 seconds) thrombin time 27 seconds (control 13) and the staphylococcal clumping test was positive.

In the course of five weeks the patient's B.U.N., creatinine and urine output slowly returned to normal. On the 19th post-operative day the partial thromboplastin time was 31 seconds (control 30 ) and the prothrombin time 15 seconds (control 11.6).

The patient received a total of 15 units of packed cells during resuscitation, operation and the immediate postoperative period. Although the patient's blood type was $\mathrm{AB}$ Rh positive the blood administered was type $\mathrm{A}$ Rh positive, 11 units; type $O$, Rh positive, 3 units; type $O \mathrm{Rh}$ negative 1 unit. All blood was re-examined 
and found compatible. There was never any evidence of haemolysis, haemoglobinaemia or haemoglobinuria. A test for urine myoglobin was negative.

The patient is now doing well, except for hypertension (180/120), and persistent foot drop.

\section{Discussion}

Disseminated intravascular coagulation or defibrination should be considered a pathological hyper-reactivity of the blood clotting system, triggered by one or more of several mechanisms, with the production of thrombin and consequent change of fibrinogen into fibrin. There is subsequent deposition of fibrin in blood vessels, consumption of clotting factors and the paradoxical development of an haemorrhagic diathesis. Variations in normal function are then due to diffuse occlusion of small blood vessels by fibrin deposits in many organs and, an increased tendency to bleed.

In our patient, transection of two major vessels, the femoral artery and vein, caused injury to endothelial cells and contact of blood with the collagen basement layer of blood vessels. This contact activates Hageman factor XII, ${ }^{4}$ which in turn activates factors, XI, IX and VIII leading in succession to the formation of activated factor $\mathrm{X}$, transformation of prothrombin to thrombin, and the hydrolysis of tibrinogen to fibrin. Thus the "intrinsic clotting system" was activated.

Extensive tissue injury such as the muscle trauma in this patient, will release thromboplastin directly into the circulation. This again will lead to the formation of thrombin and fibrin. ${ }^{4.5}$ Thromboplastin is also activated by contact with endothelial basement membrane. This is the "extrinsic clotting system."

The blood clotting system is a finely tuned set of checks and balances. Ordinarily, the liver is relied upon to clear activated factors and fibrin/fibrinogen breakdown products and the reticuloendothelial system to clear larger molecules and even particulate substances such as fibrin strands, tissue thromboplastin and fibrin monomer. ${ }^{0}$ Perhaps the patient's bout of hepatitis so altered hepatic function as to limit his clearing mechanisms. Transaminase levels measured post-operatively were elevated, but it is speculative how much of the elevation was due to liver disease, and how much to trauma, and muscle cell destruction.

Acidosis and stagnant blood flow are also thought to contribute to the development of D.I.C., ${ }^{6,7}$ Circulation in the oedematous, ischaemic leg was certainly stagnant. The decreased blood flow in the limb, coupled with hypovolaemic shock and in adequate peripheral blood flow undoubtedly caused widespread hypoxia, with change of aerobic to anaerobic metabolism and the consequent production of lactic and pyruvic acids. The hyperkalaemia was probably due to renal failure.

The diagnosis of D.I.C. depends upon recognition of the consumption of several plasma clotting factors including fibrinogen, platelets, and factors II, V, VIII, X and XIII. Thus, fibrinogen and platelet levels will be abnormally low, and prothrombin and partial thromboplastin times prolonged. Circulating breakdown products of fibrin and fibrinogen have an anti-thrombin action and will prolong the thrombin time. The deposition of fibrin in blood vessels and subsequent red cell damage often produce a microangiopathic picture on peripheral smear. ${ }^{7}$ While 
the fibrinogen of $37 \mathrm{mg} \%$ is obviously low, it must also be recognized that the levels of $324 \mathrm{mg} \%$ and $391 \mathrm{mg} \%$ are also somewhat low, since fibrinogen is usually elevated to levels of $600-1000 \mathrm{mg} \% 7$ after major surgery. While the prothrombin time and the thrombin time were still moderately prolonged on the sixth postoperative day, and while the fibrinogen and platet levels were still slightly decreased, the improvement represents termination of active D.I.C.

As a response to the induction of the clotting process, the plasmin/plasminogen fibrinolytic system is activated and serves as a limiting mechanism. This attacks fibrin and fibrinogen, producing fibrin/fibrinogen degradation products identified in this case by the staphylococcal clumping test. Identification of these degradation products confirms the increased fibrinogen turnover and/or the fibrinolytic system..$^{\mathbf{4} 8}$

The use of heparin in our patient undoubtedly limited the development of more extensive D.I.C. Its initial use was fortuitous with respect to the coagulopathy, since it was intended to prevent the development of further thrombi and emboli following arterial repair. Heparin, limits coagulation on consequent consumption of the clotting factors, by a multi-faceted attack upon the clotting process, ${ }^{0}$ thus constituting a primary therapeutic measure against D.I.C. ${ }^{4,10}$ The administration of fibrinogen would cure only one of the clotting deficiencies, while at the same time supplying more substrate for the creation of fibrin and also carrying the risk of hepatitis. ${ }^{11}$

The fibrin end-product of the D.I.C. process is precipitated diffusely, especially in the finer vessels of the lungs, mesentery and kidneys. ${ }^{1,2}$ It produces effects far outlasting the coagulopathy. In dogs with experimental D.I.C. renal vascular resistance was markedly increased and renal blood flow decreased 73 per cent. ${ }^{1}$ Not only fibrin but also platelet thrombi may be found in the glomeruli following the infusion of thrombin. This decrease in renal blood flow in our patient was undoubtedly exacerbated by a further increase in renal vascular resistance caused by arteriolar vasoconstriction associated with the use of cyclopropane. ${ }^{12}$ This pharmacological reduction in blood flow to the kidney, coupled with thrombotic occlusion of the renal vasculature, will prevent the osmotic diuretic mannitol from reaching and crossing the glomerular membrane and producing its osmotic effect, and the furosemide diuretic from reaching and acting upon the renal tubules. Thus diuretic resistant oliguric renal failure will occur and persist until fibrinolysis has re-established patency of the renal arterioles.

\section{SUMMARY}

A 22-year-old man suffered a stab wound of the femoral artery and vein. This was followed by disseminated intravascular coagulation. Renal failure then occurred presumably due to fibrin deposition in the small vessels of the kidney. The D.I.C. was successfully treated with heparin and the renal failure with peritoneal dialysis. It is suggested that D.I.C. and consequent alterations in regional blood flow following trauma are not uncommon, and search should be made for these phenomena in every case of major trauma. 


\section{RÉSUMÉ}

Un jeune homme de 22 ans a présenté un épisode de coagulation intravasculaire disséminée à la suite d'une plaie pénétrante de l'artère et de la veine fémorale.

Il s'en est suivi un épisode d'insuffisance rénale présumément secondaire à des dépôts de fibrine dans les capillaires rénaux.

L'évolution de la maladie a été favorable grâce à l'administration d'Héparine et à dialyse péritonéale.

Les auteurs suggèrent que l'incidence de coagulation intra-vasculaire disséminée avec des modifications des circulations régionales, n'est pas rare dans les traumatismes et ils concluent que l'on devrait rechercher ces phénomènes dans les cas de traumatismes majeurs.

\section{REFERENCES}

1. HoIE, J, \& SCHENK, W.G. Hemodynamics of disseminated intravascular coagulation effect; of intra-aortic thrombin infusion on renal and mesenteric blood flow in the dog. Arch. Surg. 104: 838 (1972).

2. Bergentz, S. Ljunqvist, A., \& Lewis, D.H. The distribution of platelets, fibrin, and erythrocytes in various organs following thrombin infusion: an experimental study in dogs with and without antifibrinolytic therapy. Surgery $71: 190$ (1972).

3. Berne, T.V. \& Barbour, B.H. Acute renal failure in general surgical patients. Arch. Surg. 102: 594 ( 1971$)$.

4. Colman, R.W., Robroy, S.J., \& MinNa, J.D. Disseminated intra-vascular coagulation (D.I.C. ): an approach. Amer. J. Med. 52: 679 (1972).

5. Nalbandian, R.M., Henny, R.L., Kessler, D.L., Camp, F.R., \& Wolf, P.L. Consumption coagulopathy: Practical principles of diagnosis and management. Human. Path. 2: 377 (1971).

6. Damus, D.S. \& Salzman, E.W. Disseminated intravascular coagulation. Arch. Surg. 104: $262(1972)$

7. Deykin, D. The clinical challenge of disseminated intravascular coagulation. New Eng. J. Med. 283: 636 (1970).

8. Clarkson, A.R., Sage, R.E., \& Lawrence, J.R. Consumption cogulopathy and acute renal failure due to gram-negative septicemia after abortion. Ann. Int. Med. 70: 1191 (1969).

9. Levine, W.G. Anticoagulants heparin, bishydroxycoumarin, and congeneric substances, the pharmacological basis of therapeutics. 3rd ed. Ed. by L.S. Goodman \& A. Gilman, New York, Macmillan Co. (1966).

10. Whaun, J.M. \& OskI, F.A. Experience with disseminated intravascular coagulation in a children's hospital. Canad. Med. Assoc. J. 107: 963 (1972).

11. Waxman, B. \& Gambrill, R. Use of heparin in disseminated intravascular coagulation. Amer. J. Ob-Gyn. 112: 434 (1972).

12. Deutsch, S., Pierce, E.C., \& Vandam, L.D. Cyclopropane effects on renal function in normal man. Anesthesiology 28: 547 (1967). 